APURDUTM

Euskal ikerketen aldizkaria | Revue d'études basques |

Revista de estudios vascos | Basque studies review

$7 \mid 2002$

Numéro VII

\title{
Zubereraren herskariak : azterketa akustikoa
}

Iñaki Gaminde, José Ignacio Hualde et Jasone Salaberria

URL : http://journals.openedition.org/lapurdum/1000

DOI : 10.4000/lapurdum. 1000

ISSN : 1965-0655

Éditeur

IKER

Édition imprimée

Date de publication : 1 octobre 2002

Pagination : 221-236

ISBN : 2-86781-321-2

ISSN : $1273-3830$

Référence électronique

Iñaki Gaminde, José Ignacio Hualde eta Jasone Salaberria, « Zubereraren herskariak : azterketa akustikoa », Lapurdum [Linean], 7 | 2002, Sarean emana----an 01 juin 2009, kontsultatu 30 avril 2019. URL : http://journals.openedition.org/lapurdum/1000 ; DOI : 10.4000/lapurdum.1000 


\title{
Zubereraren herskariak : azterketa akustikoa
}

\author{
Iñaki GAMINDE, \\ Euskal Herriko Unibertsitatea \\ José Ignacio HUALDE \\ Jasone SALABERRIA \\ IKER UMR 5478 CNRS
}

\begin{abstract}
Some northern varieties of Basque possess three series of plosive or oral stop

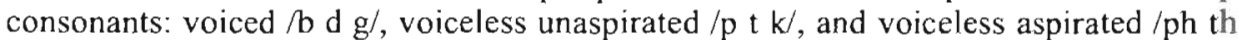
$\mathrm{kh}$. Among the languages of Europe, Basque seems to be unique in presenting this three-way opposition (although a similar contrast was found in Ancient Greek and it is not unusual in other parts of the world). For this reason it is important to document this phonological contrast; even more so since the dialects that maintain this contrast (which is believed to have been much more general in Basque in the past) appear to be in serious danger of extinction. For the study reported here, data were collected from 4 male speakers of Zuberoan or Souletin, the easternmost Basque dialect using a highquality digital recorder. The data were then analyzed using a computerized speech analysis sytem (Ahotsa, developed by I. Hernaez). Voice Onset Time (VOT) measurements were taken, since this acoustic dimension has been proven to have an excellent correlation with voicing and aspiration in many other languages. The results agree with those that have been reported for other languages with a similar three-way contrast. In utterance-initial position, $/ \mathrm{b} \mathrm{d} \mathrm{g/} \mathrm{are} \mathrm{prevoiced} \mathrm{(negative} \mathrm{VOT),} / \mathrm{p} \mathrm{t} \mathrm{k} /$ have present a short lag (VOT around $20 \mathrm{~ms}$ ) and the aspirated $/ \mathrm{ph}$ th $\mathrm{kh} / \mathrm{present}$ a much longer lag (average VOT between 60 and $80 \mathrm{~ms}$ depending on the place of articulation of the consonant).
\end{abstract}

\section{Sarrera}

Jakina denez, iparraldeko euskarak /ph th $\mathrm{kh} /$ herskari ahoskabe hasperendunak ditu (edo, hobe esan, ipar-ekialdekoak, kostatarrak galdu baititu). Hizkuntzalari batzuek zalantzan jarri dute soinu hauen estatus fonemikoa, beraien banaketa oso aldakorra delako (adib. khorpitz korphitz). Hala erc, Lafonek (1958) frogatu zuen zubereran behintzat ahoskabe hasperendunak eta hasperengabeak fonema desberdinak direla. Nahiz eta hizkeren artean desadostasunak aurkitu, hizkera jakin batean, hitz jakin bat beti modu berean ahoskatzen da: hasperendunarekin ala hasperengabearekin.

"Dans un mot donné, une occlusive sourde est toujours prononcée de la même façon: non-aspirée dans tel mot, aspirée dans tel autre.... Le $\mathrm{p}$ de iphar 'nord', le $\mathrm{t}$ de ürthe 'année', le $\mathrm{k}$ de ekhárri 'apporte' sont toujours aspirés, tandis que le p de ttipi 'petit', le t de árte 'intervalle' et le k de jákin 'su' ne le sont jamais. Le k de lékhü 'lieu, endroit' (de latin locum) est aspiré; celui de jókü 'jeu' (de lat. iocum) ne l'est pas." (Lafon 1958: 90). 
Badira, izan ere, pare minimo batzuk, nahiz eta ez asko : merkatu 'merkeagotu' vs. merkhatu 'azoka'.

Munduko beste hizkuntza batzuek badute ahostun / ahoskabe hasperengabe / ahoskabe hasperendun (edo b/p/ph, laburtuz) bereizkuntza hirukoitza, baina Europan euskara da kasu ezagun bakarra (aitzineko grezieraz ere ematen zen). Arrazoi honegatik fenomeno interesgarria da eta aztertzea merezi du. Guk dakigunez, orain arte, inork ez du aztertu bereizketa hau nola gauzatzen den zubereraz. Lan honen helburua $\mathrm{b} / \mathrm{p} / \mathrm{ph}$ bereizkuntza hirukoitza fonetikoki nola gauzatzen den aztertzea da.

\section{2. $\mathrm{p} / \mathrm{b} / \mathrm{ph}$ bereizkuntzaren ikerketa fonetikoa}

Artikulu garrantzitsu batean, Lisker \& Abramson-ek (1964) erakutsi zuten ahoskabe/ahostun edo-ta hasperengabe/hasperendun bereizkuntzan ezaugarri fonetiko nagusia ahotsaren hasieragunea edo, ingelesez, voice onset time (VOT) bezala ezagutzen dena dela. Ordutik hona, beste ikerketa lan askotan VOTaren garrantzia frogatu da (Flege 1982, Keating 1984, beste askoren artean).

Herskari bat ahoskatzeakoan, bi fase ditugu: hersketa eta leherketa (horregatik herskari eta leherkari izenak). Herskariaren ondoren bokal bat badaukagu, ahots-korden dardar periodikoa hiru momentu desberdinetan has daiteke:

1) Ahots-korden dardarra kontsonantearen leherketa baino lehen hasten bada, herskari ahostun bat izango dugu, [ba da ga].

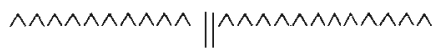

2) Ahots-korden dardarra leherketarekin batera edo apur bat beranduago hasten bada, herskari ahostun hasperengabea izango dugu, [pa ta ka].

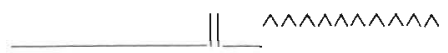

3) Azkenik, ahots-korden dardarra leherketa baino beranduxeago has daiteke. Hirugarren kasu honetan leherketaren eta uhin periodikoaren hasieraren artean hasperenketa izango dugu ondorioz eta gauzatzen den herskaria ahoskabea eta hasperenduna izango da, [pha tha kha].

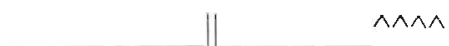

VOT delakoaren arabera, ahotsaren dardarra leherketa baino lehen hasten bada (1 kasua), VOT negatiboa izango dugu. Beste bi kasuetan, hurrenez hurren, VOT positibo laburra (2), eta VOT positibo luzea (3), izango ditugu.

Hizkuntza batzuetan, hala nola thailandieraz, hiru kategoria fonetiko hauek fonema desberdinak ematen dituzte. Thailandieraz [d] herskari ahostuna (VOT negatiboa duena), [t] herskari ahoskabe hasperengabea (VOT positibo laburra) eta [th] herskari ahoskabe hasperenduna (VOT positibo luzea) hiru fonema desberdin dira.

Beste hizkuntza askotan, aldiz, hauetariko bi kategoria bakarrik bereizten dira. Hizkuntza erromanikoetan eta gaurregungo euskalki gehienetan ahostunak 
eta ahoskabe hasperengabeak ditugu ( 1 eta 2 klaseak). Lehen irudian gaztelaniazko cota/gota pare minimoa erakusten da. Ikus dezakegunez, gotaren lehen kontsonateak VOT negatiboa duen bitartean, cota-ren lehen kontsonanteak VOT positibo laburra erakusten du. Hizkuntza honetan ez dugu VOT positibo luzeko herskaririk (ikus Wiliams 1976, adibidez).

\section{Irudia.}

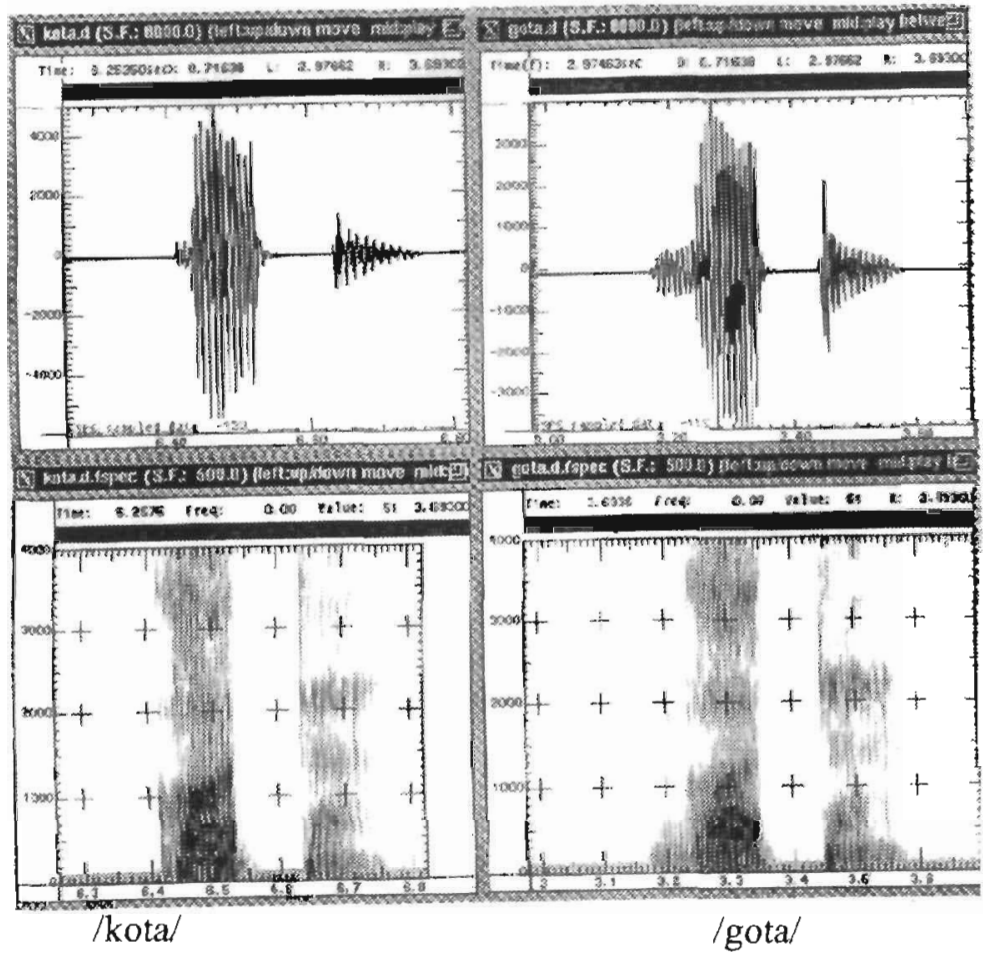

Ingelesez edo alemanez ere bi kategoria bakarrik bereizten dira baina gauzak zeharo desberdinak dira fonetikaren aldetik. Nahiz eta hizkuntza hauetan fonologikoki antzeko bereizketa bitarra izan, gauzatze fonetikoa nahikoa bestelakoa da. Bigarren irudian ingelezko coat/goat parea erakusten da (hiztuna amerikarra da). Lehen eta bigarren irudiak erkatzen ditugunean, gaztelaniaren hasierako / $\mathrm{k}$-/ eta ingelesaren /g-/ soinua antzekoak direla ikusten dugu : biek VOT positibo laburra dute (goat eta cota konpara itzazue). Hau da, ingelesezko adibide honetan, /g-/ hasierako herskaria ahoskabea da fonetikoki. Adibide hau ez da bitxia. Guztiz alderantziz, ingelesez $/ \mathrm{b} d \mathrm{~g} /$ soinuak gehienetan ahoskabeak dira hasiera absolutuan, hau da, $[\mathrm{p} \mathrm{t} k]$. Dena den, hiztun batzuek ahostunak bezala ahoskatzen dituzten. Lehen eta bigarren kategoria fonetikoak neutralduta daude ingelesez. Hitz hasieran VOT negatiboko eta VOT positibo laburreko herskariak alofonoak dira hizkuntza honetan (Lisker \& Abramson 1964, Flege 1982). Bestaldetik, /p t k/ kontsonante ahoskabeek VOT positibo luzea dute, hasperendunak dira, [ph th kh], bigarren irudiko coat adibidean ikusten den bezala. Beraz, gaztelaniaz 1. eta 2. tipoak kontraste fonemikoan dauden bitartean, inglesez 1. eta 2. tipoak 
fonema ahostunen alofonoak dira hasiera absolutuan eta 3. tipoko kontsonanteekin kontrastatzen dira.

\section{Irudia :}

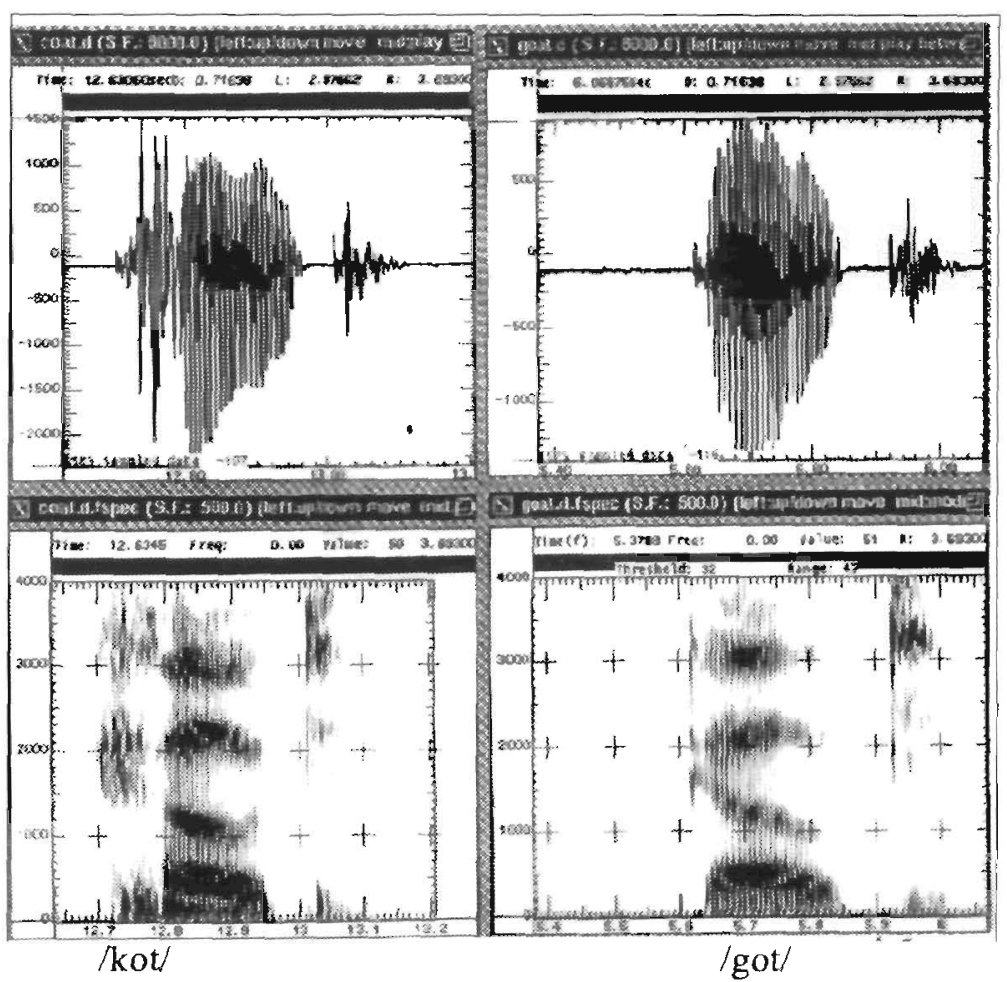

Esan duguna hasierako gunean dauden herskariei dagokie. Beste ingurune batzuetan kontraste fonologikoa beste ezaugarri fonetiko batzuen bidez gauzatzen da.

\section{Esperimentua}

Hemen aurkezten ditugun datuak jaso ahal izateko lau lekukoren laguntza izan dugu. Lekuko guztiak gizonezkoak izan dira eta 60 urte ingurukoak. Euren jatorriei dagokienez, Gamere, Ürrüxtoi, Eskiula eta Barkoxekoak izan dira; ondoko mapa honetan herrion kokaera ikus daiteke : 
Galdekizuna prestatzeko Larrasquet-en (1939) hiztegia erabili genuen, bertan hasierako gunean herskari hasperendunarekin agertzen diren hitz guztien zerrenda bat osatuz. Azentudun azentugabe aldagaia ekiditeko, neurtuko genuen soinua silaba azentudunekoa izatea erabaki genuen. Horretarako hasierako zerrenda hartatik silaba bi baino gehiagoko hitzak baztertu genituen, hala nola azentua bigarren silaban daukatenak ere. Bestalde, beronek inplikatzen du hitza mugagabe erara emateko ere eskatu dugula. Horrela bada "bérde", "bórda", "bágo", "beltz" eta "gor" moduko hitzak baino ez ditugu erabili. Erabilitako zerrenda osoa lehen eranskinean ikus daiteke.

Datuak jasotzeko metodologiari dagokionez, behin galdekizuna edukiz geo lekukoei frantzesez eskatzen genizkien hitzak eurek euskaraz emateko; grabazioak lekukoen ingurugiroan egin ziren. Datu guztiak DAT eta MiniDisc sistema digitalen bidez jasoak izan dira, beti ere kanpo mikrofono bat erabiliz. Behin datuak jasota, PC ordenagailu baten sartu eta Inmaculada Hernáezek garatutako "Ahotsa" aztergailuaren bidez neurtu genituen.

Neurriak egiterakoan VOTa neurtu dugu. Nola leherketa barra sarritan argi ez den agertzen, ahostunen kasuan bereziki, halatan deliberatu genuen dardar periodikoa hasten denetik bokalaren formakinak egonkor bihurtzen direnerainoko zatia neurtzea. Ahoskabeen kasuan modu berean egin genituen neurketa guztiak.

Soinu bakoitzerako adibide baten ahots-uhina eta espektrograma ematen ditugu bigarren eranskinean, lan honetako bukaeran.

\section{Emaitzak}

Esperimentuaren emaitzak aurkezteko lehendabizi eurok herriz herri nola gauzatu diren ikusiko dugu, herri bakoitzerako hiztun bakarra dugularik. Emaitza guztiak milisegundotan adierazirik emango ditugu.

\section{Gamere (denetara 64)}

\begin{tabular}{|c|c|c|c|c|}
\hline & Batezbestekoa & Desbiazioa & Kopurua & Rangoa \\
\hline $\mathrm{b}$ & -123 & 13 & 9 & $104-142$ \\
\hline $\mathrm{d}$ & -116 & 23 & 6 & $74-137$ \\
\hline $\mathrm{g}$ & -109 & 14 & 7 & $92-128$ \\
\hline $\mathrm{p}$ & 22 & 5 & 10 & $14-30$ \\
\hline $\mathrm{t}$ & 20 & 4 & 4 & $14-24$ \\
\hline $\mathrm{k}$ & 21 & 2 & 5 & $18-24$ \\
\hline $\mathrm{ph}$ & 65 & 12 & 9 & $52-88$ \\
\hline $\mathrm{th}$ & 63 & 8 & 5 & $54-76$ \\
\hline $\mathrm{kh}$ & 80 & 11 & 9 & $68-99$ \\
\hline
\end{tabular}




\section{Gamere}

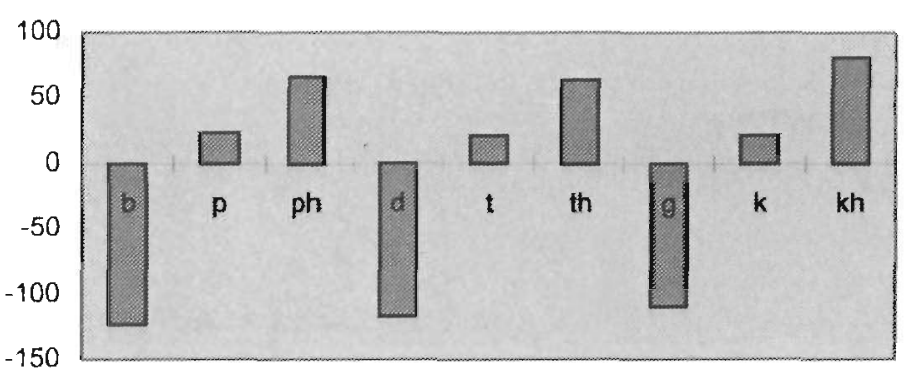

Eskiula (denetara 86)

\begin{tabular}{|c|c|c|c|c|}
\hline & Batezbestekoa & Desbiazioa & Kopurua & Rangoa \\
\hline $\mathrm{b}$ & -78 & 14 & 13 & $56-99$ \\
\hline $\mathrm{d}$ & -66 & 10 & 10 & $54-84$ \\
\hline $\mathrm{g}$ & -63 & 12 & 11 & $50-87$ \\
\hline $\mathrm{p}$ & 20 & 5 & 11 & $15-33$ \\
\hline $\mathrm{t}$ & 22 & 5 & 7 & $15-29$ \\
\hline $\mathrm{k}$ & 28 & 6 & 5 & $23-39$ \\
\hline $\mathrm{ph}$ & 58 & 12 & 11 & $41-79$ \\
\hline $\mathrm{th}$ & 55 & 7 & 8 & $45-70$ \\
\hline $\mathrm{kh}$ & 70,5 & 11 & 10 & $46-84$ \\
\hline
\end{tabular}

Eskiula

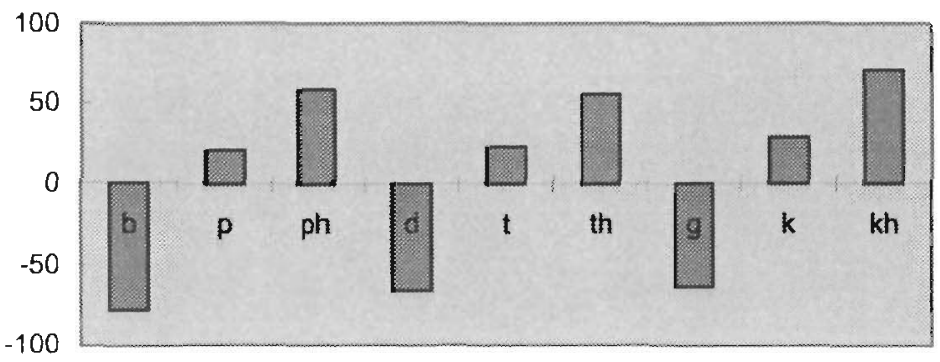




\section{Barkoxe (denetara 79)}

\begin{tabular}{|c|c|c|c|c|}
\hline & Batezbestekoa & Desbiazioa & Kopurua & Rangoa \\
\hline $\mathrm{b}$ & -121 & 21 & 13 & $86-150$ \\
\hline $\mathrm{d}$ & -115 & 10 & 6 & $98-124$ \\
\hline $\mathrm{g}$ & -126 & 19 & 13 & $99-162$ \\
\hline $\mathrm{p}$ & 17 & 5 & 12 & $10-25$ \\
\hline $\mathrm{t}$ & 20 & 1 & 5 & $18-21$ \\
\hline $\mathrm{k}$ & 22 & 4 & 6 & $15-26$ \\
\hline $\mathrm{ph}$ & 60 & 10 & 9 & $51-79$ \\
\hline $\mathrm{th}$ & 78 & 7 & 6 & $68-91$ \\
\hline $\mathrm{kh}$ & 92 & 12 & 9 & $77-114$ \\
\hline
\end{tabular}

\section{Barkoxe}

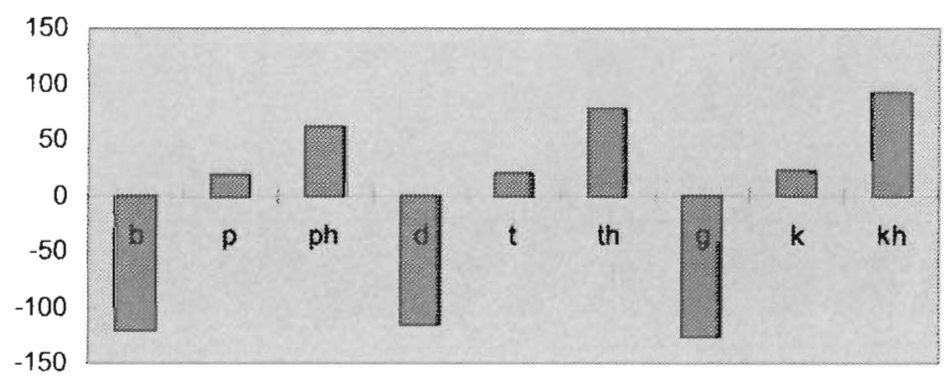

\section{Ürrüxtoi (denetara 73)}

\begin{tabular}{|c|c|c|c|c|}
\hline & Batezbestekoa & Desbiazioa & Kopurua & Rangoa \\
\hline $\mathrm{b}$ & -84 & 12 & 13 & $62-102$ \\
\hline $\mathrm{d}$ & -122 & 16 & 5 & $101-150$ \\
\hline $\mathrm{g}$ & -106 & 18 & 13 & $74-143$ \\
\hline $\mathrm{p}$ & 21 & 6 & 9 & 12.29 \\
\hline $\mathrm{t}$ & 33 & 6 & 4 & $24-38$ \\
\hline $\mathrm{k}$ & 38 & 6 & 5 & $33-49$ \\
\hline $\mathrm{ph}$ & 60 & 7 & 10 & $50-76$ \\
\hline $\mathrm{th}$ & 72 & 11 & 5 & $56-85$ \\
\hline $\mathrm{kh}$ & 90 & 12 & 9 & $64-106$ \\
\hline
\end{tabular}




\section{Ürrüxtoi}

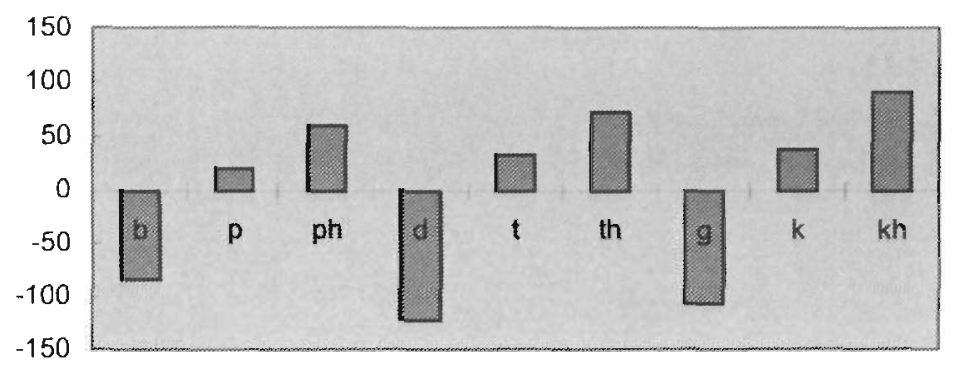

Emaitzak orotara ikusirik honako taula hau osa dezakegu :

\begin{tabular}{|c|c|}
\hline & Batezbestekoa \\
\hline $\mathrm{b}$ & -102 \\
\hline $\mathrm{p}$ & 20 \\
\hline $\mathrm{ph}$ & 61 \\
\hline $\mathrm{d}$ & -105 \\
\hline $\mathrm{t}$ & 24 \\
\hline $\mathrm{th}$ & 67 \\
\hline $\mathrm{g}$ & -101 \\
\hline $\mathrm{k}$ & 27 \\
\hline $\mathrm{kh}$ & 83 \\
\hline
\end{tabular}

Sailka hartzen baditugu, ahostunen kasuan honako grafika hau osa dezakegu :

\section{Ahostunak}

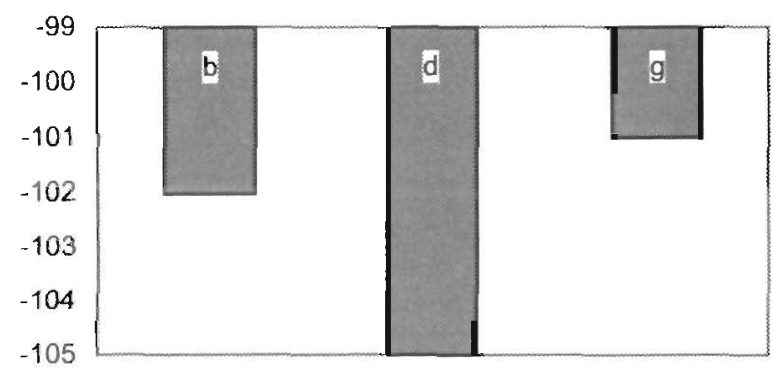


Ondoko grafikan, berriz, ahoskabe hasperendunak eta hasperengabeak: batera ikus daitezke :

\section{Ahoskabeak}

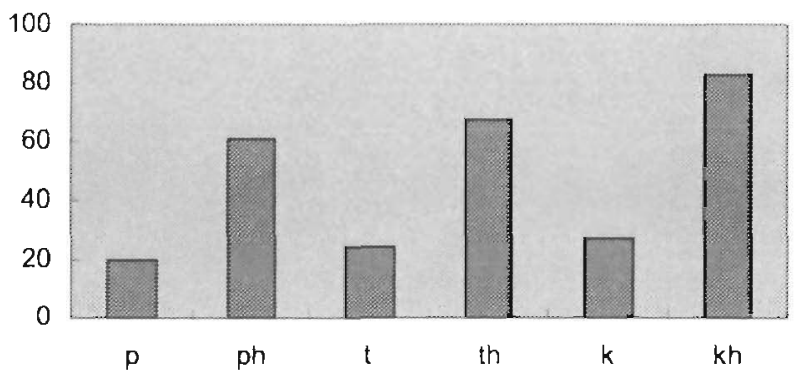

\section{Ondorioak}

Ahostunen emaitzak bazter utzita, aurreko ataleko taulen azterketatik atera dezakegun ondoriorik nabarmenena hasperendunen VOTa kasu guztietan hasperengabeena baino aisa luzeagoa izatea da. Proportzioak honako hauek dira: ph $\% 33$, th $\% 35$ eta $\mathrm{kh} \% 33$.

Lisker \& Abramson-ek bereizkuntza hirukoitza duten bi hizkuntza aztertu zituzten, ekialdeko armeniera eta thailandiera. Hizkuntza hauen emaitzak eta guk lortu ditugunak oso antzekoak dira. Ondoko taulan batezbestekoak erkatzen ditugu hiru hizkuntzetan (thailandierak ez dauka /g/ fonemarik). Konparaketarako Lisker \& Abramsonek Puerto Rico-ko gaztelaniaz aurkitu zituzten VOT datuak ere ematen ditugu:

\begin{tabular}{|c|c|c|c|c|}
\hline & zuberera & e. armeniera & thailandiera & PR gaztelania \\
\hline $\mathrm{b}$ & -102 & -96 & -97 & -110 \\
\hline $\mathrm{p}$ & 20 & 3 & 6 & 4 \\
\hline $\mathrm{ph}$ & 61 & 78 & 64 & - \\
\hline $\mathrm{d}$ & -105 & -102 & -78 & -109 \\
\hline $\mathrm{t}$ & 24 & 15 & 9 & 7 \\
\hline $\mathrm{th}$ & 67 & 59 & 65 & - \\
\hline $\mathrm{g}$ & -101 & -115 & - & -92 \\
\hline $\mathrm{k}$ & 27 & 30 & 25 & 25 \\
\hline $\mathrm{kh}$ & 83 & 98 & 100 & - \\
\hline
\end{tabular}

Diferentziarik nabarmenena /p/ eta / $t /$ fonemetan aurkitzen da. Hauek zubereraz beste hizkuntzetan baino VOT luzeagoa dute. Bestela, lau hizkuntzen emaitzak nahikoa antzekoak dira.

Ahoskabeen kasuan, bai hasperendunetan bai hasperengabeetan, zenbat eta atzerago ebaki orduan eta VOTa luzeagoa dela ere atera dezakegun beste ondorio bat da. Jarraian ematen ditugun grafiketan desberdintasun hori argi ikus daiteke : 


\section{Hasperengabeak}

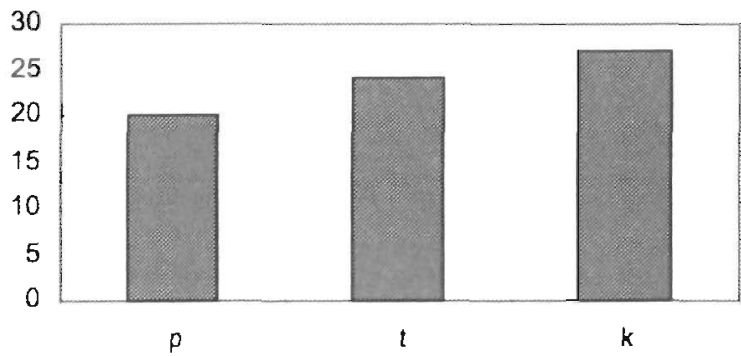

\section{Hasperendunak}

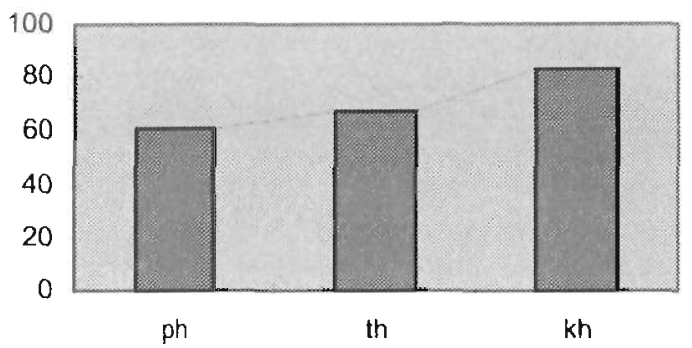

Ondorioz, zubererak hiru herskari mota ditu. VOT-aren bidez argi eta garbi bereizten dira hirurak. Bereizkuntza oposaketa hirukoitza duten beste hizkuntza batzuetan bezain garbia da.

Lana amaitu baino lehen hurrengo lanetarako proposamen batzuk egitea gelditzen zaigu. Batetik ineteresgarri ikusten dugu bokalen arteko herskariak aztertzea eta zubereraren gainerako barietateetan antzeko azterketa batzuk egitea, izan ere, hemen aukeratu ditugun herriak eskualde batekoak dira. Bestetik, gainerako euskalkien, lapurtera eta behe nafarrera, egoerak aztertzeari ere interesgarri deritzogu. 


\section{Eranskina}

Lan hau burutu ahal izateko erabilitako hitz guztien zerrenda :

\begin{tabular}{|l|l|l|l|l|}
\hline bágo & báhe & bákhio & bégi & béhi \\
\hline béle & béltz & bérde & bíde & bíhi \\
\hline bíhotz & bóhor & bórda & búha & b'üü \\
\hline dálla & dállü & dántza & débrü & déithü \\
\hline déitzez & déuse & d'üda & dÜnda & gáar \\
\hline gai & gaitz & gáiza & gáltha & gáltho \\
\hline gar & gáthü & gatz & gázte & gézi \\
\hline gézür & gízon & gor & górri & g'üne \\
\hline kánpo & kárga & kárta & káska & kénte \\
\hline khánba & khánta & khárrok & khe & khéñü \\
\hline khéta & khímer & khínber & khínper & khíño \\
\hline khóntü & khórda & khórpitz & khúnta & kh'üntü \\
\hline kh'ürlo & kh'ütxe & kólpe & kúska & pága \\
\hline pháke & phárte & phéntsa & phéña & phéska \\
\hline phésü & phézü & phíko & phíno & phíper \\
\hline phórrü & phünta & ph'ünta & ph'üntsü & ph'ützü \\
\hline píkhor & pínta & pípa & p'ünta & p'ürga \\
\hline tábal & tánta & táza & téka & télla \\
\hline tháza & théka & théyüi & thíña & thónba \\
\hline thórpe & thúnba & thü & tjéta & tótzo \\
\hline
\end{tabular}

\section{Eranskina}

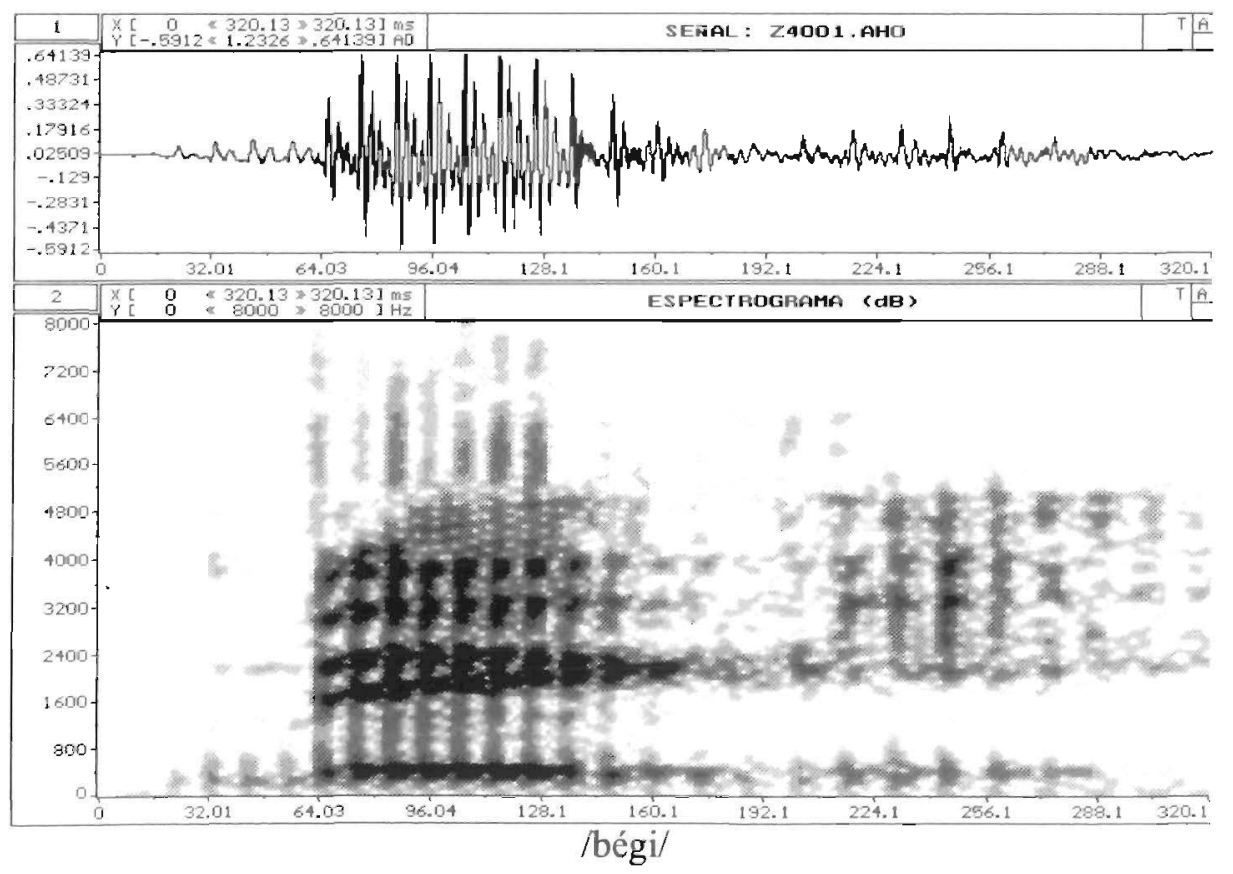



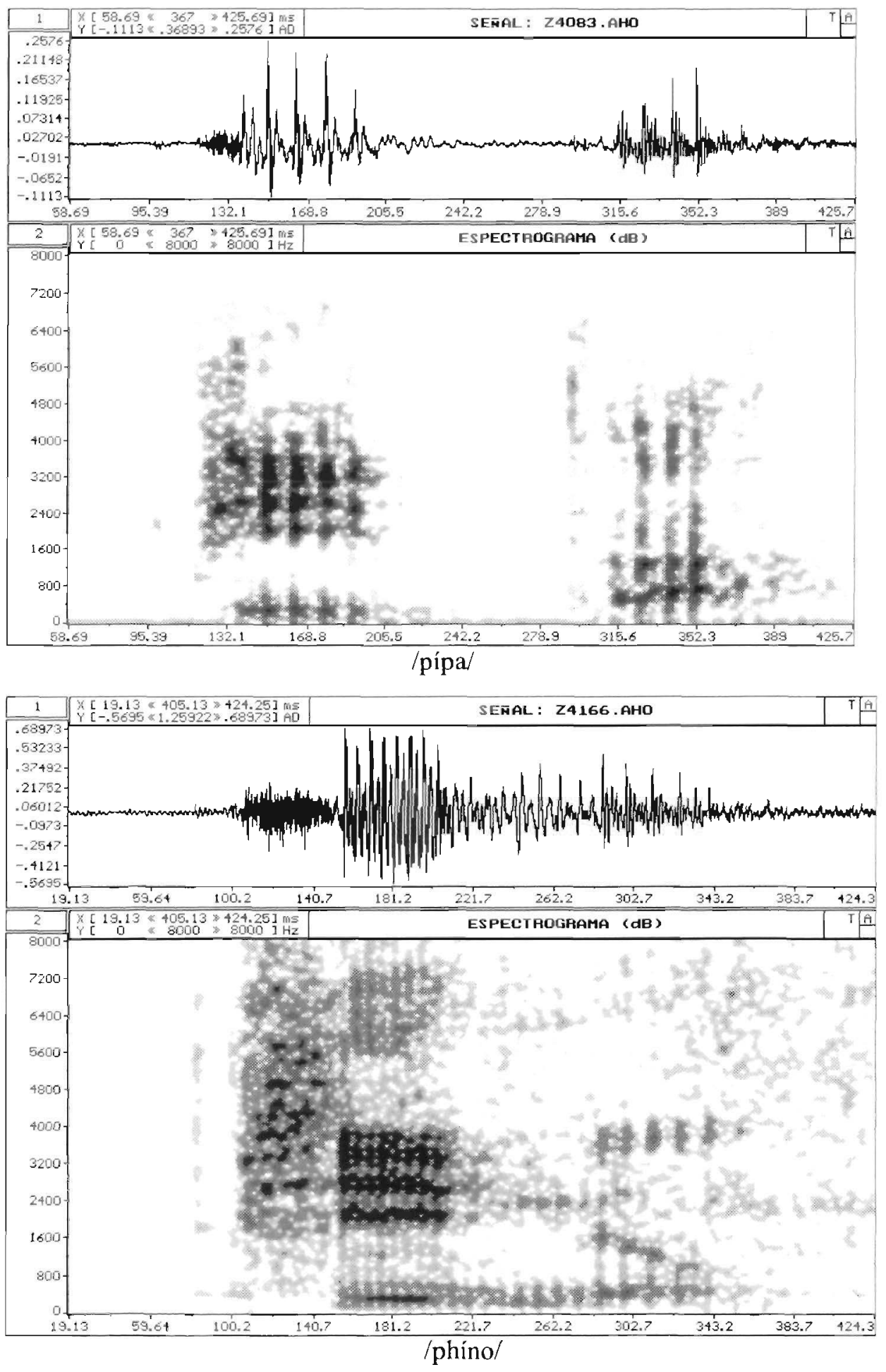

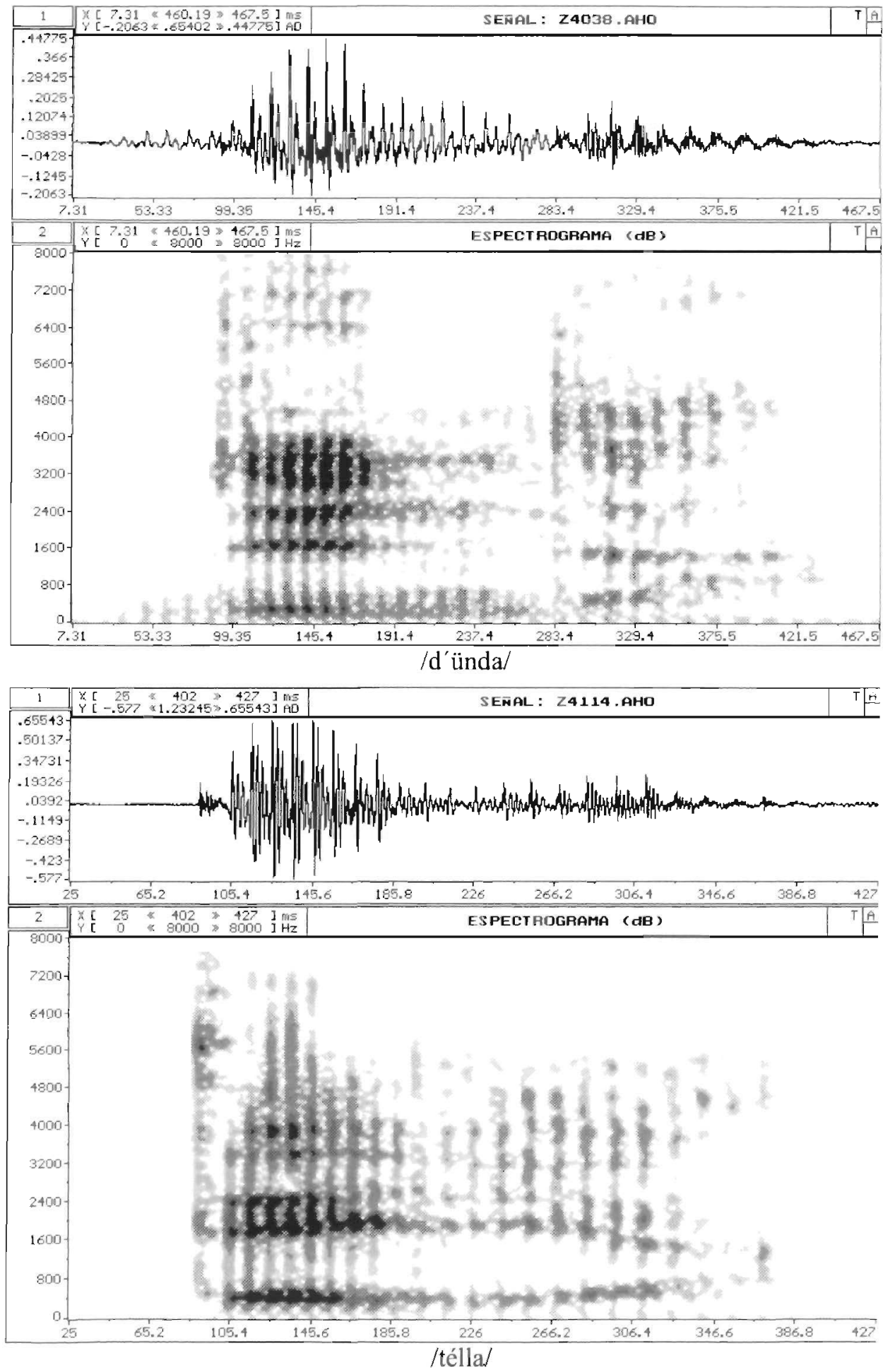

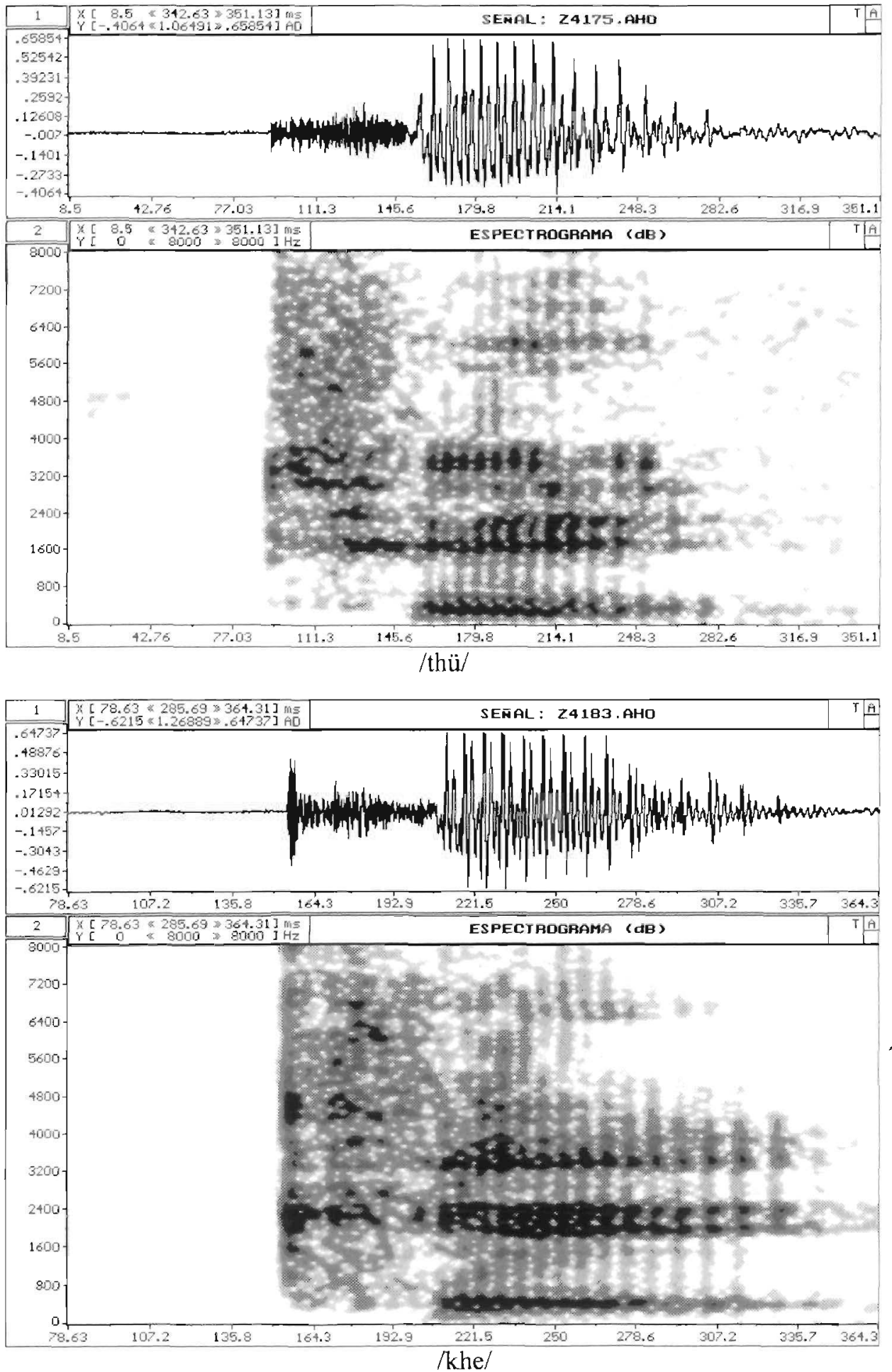


\section{Aipamen bibliografikoak}

Keating, Patricia. 1984. "Phonetic and phonological representation of stop consonant voicing". Language 60: 286-319/

Flege, James E. 1982. "Laryngeal timing and phonation onset in utteranceinitial English stops" Journal of Phonetics 10: 177-192.

Lafon, Rene. 1958. "Contribution a l'étude phonologique du parler basque de Larrau (Haute-Soule)". In Diego Catalan, arg., Miscelanea homenaje a A. Martinet, 2. lib., 77-106. La Laguna, Tenerife : Univ. de La Laguna.

Larrasquet, Jean, 1939, Le Basque de la Basse-Soule Orientale. Paris

Lisker, Leigh \& Arthur Abramson. "A cross-language study of voicing in initial stops: acoustical measurements." Word 20:384-422.

Williams, Lee. 1976. "The voicing contrast in Spanish". Journal of Phonetics 5, 169-184.

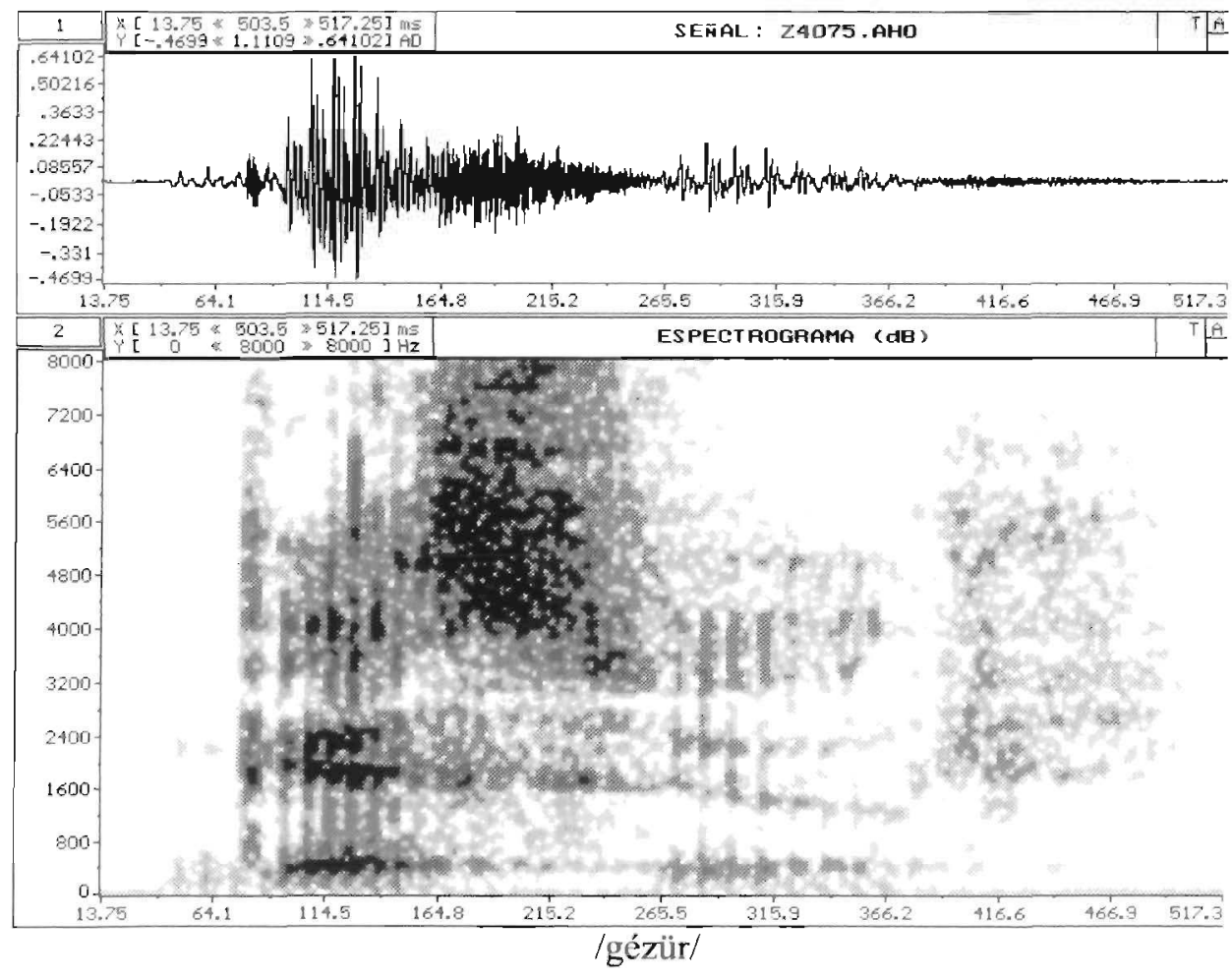




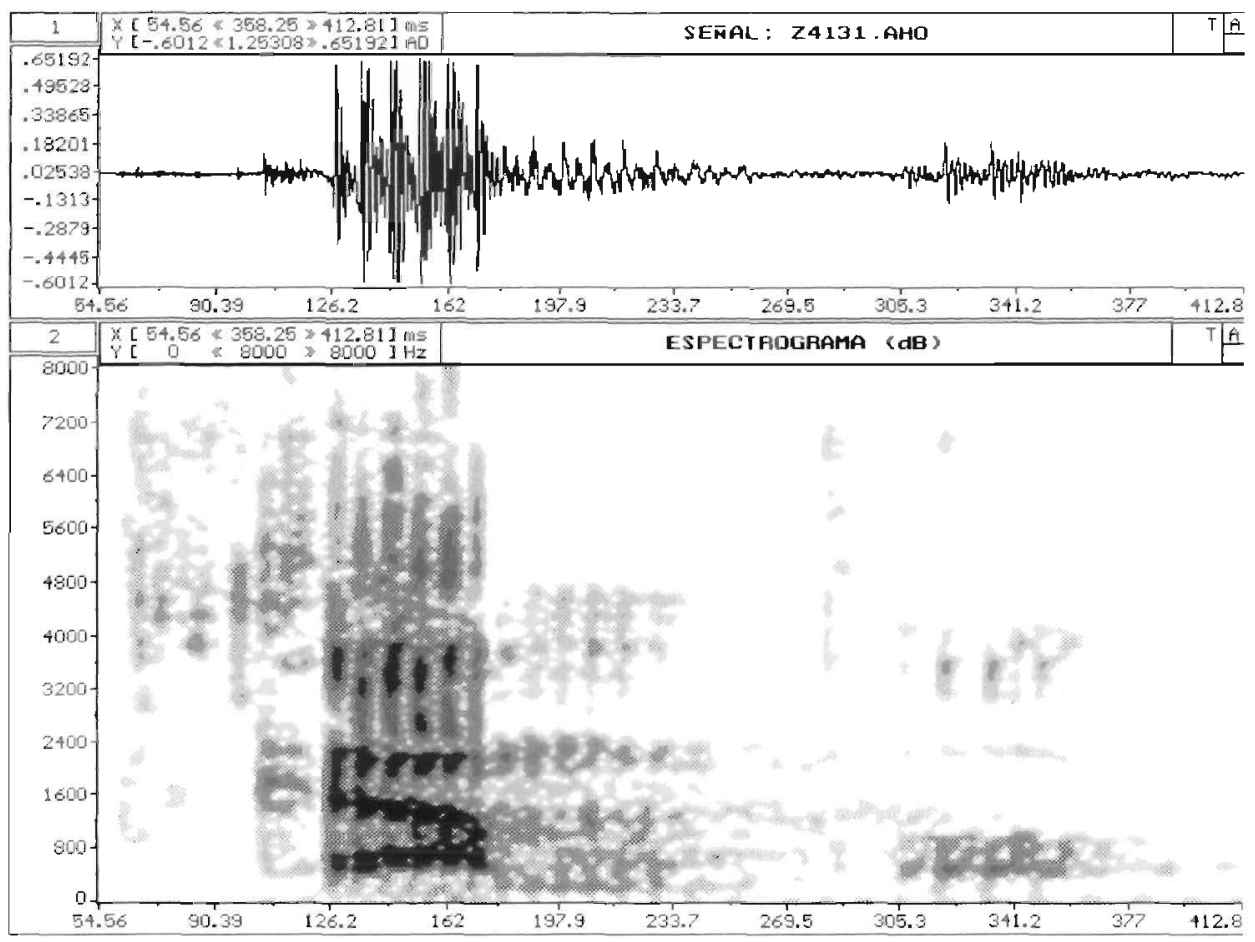

/kánpo/ 